\title{
Effect of fermented broth from lactic acid bacteria on pathogenic bacteria proliferation
}

\author{
S. Gutiérrez, ${ }^{*}$ H. Martínez-Blanco, ${ }^{*} \dagger$ L. B. Rodríguez-Aparicio, ${ }^{*} \dagger$ and M. A. Ferrero*${ }^{*}{ }^{1}$ \\ *Departamento de Biología Molecular, Facultad de Veterinaria, and \\ †Instituto de Biología Molecular, Genómica y Proteómica (INBIOMIC), Universidad de León, 24071 León, Spain
}

\section{ABSTRACT}

In this study, the effect that 5 fermented broths of lactic acid bacteria (LAB) strains have on the viability or proliferation and adhesion of 7 potentially pathogenic microorganisms was tested. The fermented broth from Lactococcus lactis $\mathrm{C} 660$ had a growth inhibitory effect on Escherichia coli K92 that reached of 31\%, 19\% to Pseudomonas fluorescens, and $76 \%$ to Staphylococcus epidermidis. The growth of Staph. epidermidis was negatively affected to $90 \%$ by Lc. lactis 11454 broth, whereas the growth of $P$. fluorescens (25\%) and both species of Staphylococcus (35\% to Staphylococcus aureus and $76 \%$ to Staph. epidermidis) were inhibited when they were incubated in the presence of Lactobacillus casei 393 broth. Finally, the fermented broth of Lactobacillus rhamnosus showed an inhibitory effect on growth of E. coli K92, Listeria innocua, and Staph. epidermidis reached values of 12,28 , and $76 \%$, respectively. Staphylococcus epidermidis was the most affected strain because the effect was detected from the early stages of growth and it was completely abolished. The results of bacterial adhesion revealed that broths from Lc. lactis strains, Lactobacillus paracasei, and Lb. rhamnosus caused a loss of E. coli K92 adhesion. Bacillus cereus showed a decreased of adhesion in the presence of the broths of Lc. lactis strains and Lb. paracasei. Listeria innocua adhesion inhibition was observed in the presence of $L b$. paracasei broth, and the greatest inhibitory effect was registered when this pathogenic bacterium was incubated in presence of Lc. lactis 11454 broth. With respect to the 2 Pseudomonas, we observed a slight adhesion inhibition showed by Lactobacillus rhamnosus broth against Pseudomonas putida. These results confirm that the effect caused by the different LAB assayed is also broth- and species-specific and reveal that the broth from LAB tested can be used as functional bioactive compounds to regulate the adhesion and biofilm synthesis and ultimately lead to

Received September 24, 2015.

Accepted December 18, 2015.

${ }^{1}$ Corresponding author: ma.ferrero@unileon.es preventing food and clinical contamination and colonization of E. coli K92, B. cereus, and Ls. innocua.

Key words: lactic acid bacteria, Lactobacillus, Lactococcus, adhesion, probiotics

\section{INTRODUCTION}

Pathogenic bacteria or toxins produced by bacteria often enter the human body through food or drink, causing symptoms or illness with several mechanisms. Staphylococcus aureus and Escherichia coli belong to the normal flora of about $50 \%$ of people, although virulent strains, resistant to commonly used antibiotics, may cause sepsis and severe infections. Food-borne intoxication is caused by a heat-stable enterotoxin produced by Staph. aureus in consumed food, which produces nausea and vomiting (Nester, 2001). Bacillus cereus contaminates various types of final food products, such as cooked chilled meals, vegetables, meat, fish, milk, liquid egg, pastries, flavorings, oils, and fats (Wijnands et al., 2006; Baron et al., 2007). On the other hand, Listeria monocytogenes is a common bacterium in the environment and in animals, and it may be transferred to food and the human gastrointestinal tract via raw milk and contaminated dairy products. This organism may cause meningitis, sepsis, or abortion, but in practice only pregnant women and people with immune defects are in danger of catching the infection (Nester, 2001). Staphylococcus epidermidis, commensal coagulase-negative, may be transferred to the human gastrointestinal tract via breast milk because this microorganism belongs to skin microbiota (Iwase et al., 2010; Park et al., 2011).

Probiotics are defined as living microorganisms which act to keep the balance of intestinal microbiota after ingestion in sufficient numbers (Fuller, 1989). Lactic acid bacteria (LAB) are probiotic microorganisms known to produce antibacterial peptides and small proteins called bacteriocins, which enable them to compete against other bacteria in the environment. Lactic acid bacteria, such as Lactobacillus species, have protective effects against a variety of pathogenic infections in the gastrointestinal systems of humans and animals (Ahrné et al., 1998; Gill et al., 2001). These strains produce 
a wide range of antimicrobial agents and have been studied extensively with regard to their possible use in the field of probiotics. This bacteria may also be a useful alternative for the treatment and prevention of a variety of infectious diseases caused by oral, enteric, and urogenital pathogens (Shornikova et al., 1997; Caglar et al., 2006; Abad and Safdar, 2009).

Recently, probiotics have been studied principally for their potential as an alternative to antibiotics in the field of livestock production (Reid and Friendship, 2002; Reid, 2006). Commonly used probiotics such as Bacillus, Lactobacillus, Bifidobacterium species, and Clostridium butyricum have the potential to improve swine growth performance, to increase utilization of nutrients such as dietary starch, and to resist colonization by pathogens in the gastrointestinal tract of animals (Lee et al., 2001; Guo et al., 2006). Many studies suggest that LAB could protect sites against pathogenic bacterial invasion and colonization by preventing the attachment of these pathogens to sites. Lactic acid bacteria produce substances that inhibit the multiplication of pathogens by competing with other microorganisms for nutritional requirements. This might inhibit the multiplication of these agents by excreting substances, mainly $\mathrm{H}_{2} \mathrm{O}_{2}$, lactic acid, and bacteriocinlike substances (Andreu et al., 1995; Cadieux et al., 2002). Furthermore, the effect on growth is important when studying the relations established between different bacterial species. It is now known that only a very small fraction of bacteria are in the form of free-floating plankton. It is postulated that $99 \%$ of all bacterial cells exist as biofilms and only $1 \%$ live in a planktonic state (Ramadan et al., 2005; Sanclement et al., 2005). The development of biofilm communities is one of the main strategies for bacteria survival in a certain ecological niche. This state allows bacteria integrated into the biofilm to be protected from environmental fluctuation factors such as humidity, temperature, and $\mathrm{pH}$ and, in the case of infections antibacterial preparations applied to the host organism, lengthen the infection and also provide concentrated nutrients and waste disposal. In recent years interest has increased in eating healthy foods, mainly due to possible beneficial effects on the body.

In our laboratory, we studied different strains that may have probiotic potential (Monteagudo-Mera et al., 2011; Monteagudo-Mera et al., 2012). We then decided to focus on studying the competition that can exist between potentially probiotic bacterial strains and those that may be considered potentially pathogenic, both of which are common in the intestinal microbiota of the mammals. The former have been selected because of their antimicrobial activity and to achieve the displacement of potentially pathogenic strains from dairy products that could attached to the gastric epithelium. The latter were chosen because of their presence and their possible capacity to adhere to the gastrointestinal epithelium. Our aim was to establish the characteristics that inhibit or reduce the growth of potentially pathogenic strains and enhance the proliferation of probiotic to increase the added value of functional foods. The objective we propose in this paper is, therefore, to determine the effect that different fermented broths of LAB strains have on the viability or proliferation and adhesion of potentially pathogenic microorganisms.

\section{MATERIALS AND METHODS}

\section{Strains and Culture Conditions}

To carry out this work, we studied 5 strains of LAB, obtained from the bacterial culture collection of the Department of Hygiene and Food Technology, at the University of León (these were isolated from human feces or milk products) and from the American Type Culture Collection (ATCC, Manassas, VA), which were selected according to their probiotic and antimicrobial properties (Monteagudo-Mera et al., 2011, 2012). Meanwhile, 7 potentially pathogenic strains were used; these came from the ATCC, Spanish Collection of Type Culture (Paterna, Spain), and the Culture Collection of the Hannah Research Institute (Ayr, Scotland), which were selected based on their potential as food contaminants (Tables 1 and 2).

All LAB strains were grown in trypticase soy broth (TSB) containing $0.6 \%(\mathrm{wt} / \mathrm{vol})$ yeast extract at $30^{\circ} \mathrm{C}$ for $24 \mathrm{~h}$, with the exception of Lactobacillus casei ATCC 393, which was incubated for $36 \mathrm{~h}$ at the same temperature. Potentially pathogenic strains were cultured in the same medium, but at $37^{\circ} \mathrm{C}$ for $12 \mathrm{~h}$, except Pseudomonas fluorescens and Pseudomonas putida, which were incubated at $30^{\circ} \mathrm{C}$. When it was necessary, the strains were grown on trypticase soy agar (TSA) petri plates or TSA slant tubes under the same growth conditions as TSB with yeast extract medium. The strains were maintained in a mixture of TSB-glycerol $(1: 1)$ at $-80^{\circ} \mathrm{C}$ until further use.

\section{Determining the Effect of $L A B$ on Pathogenic Bacterial Growth}

To determine the potential inhibitory effect of LAB over pathogenic bacteria, both strain types were grown in TSA slant tubes at the appropriate temperature (see above) and time (Monteagudo-Mera et al., 2011), and when the optimal growth was reached, the cells were resuspended in $4 \mathrm{~mL}$ of TSB. The bacterial grown was evaluated by measuring optical density (OD) at $620 \mathrm{~nm}$ 
Table 1. Lactic acid bacteria (LAB) strains used in this study

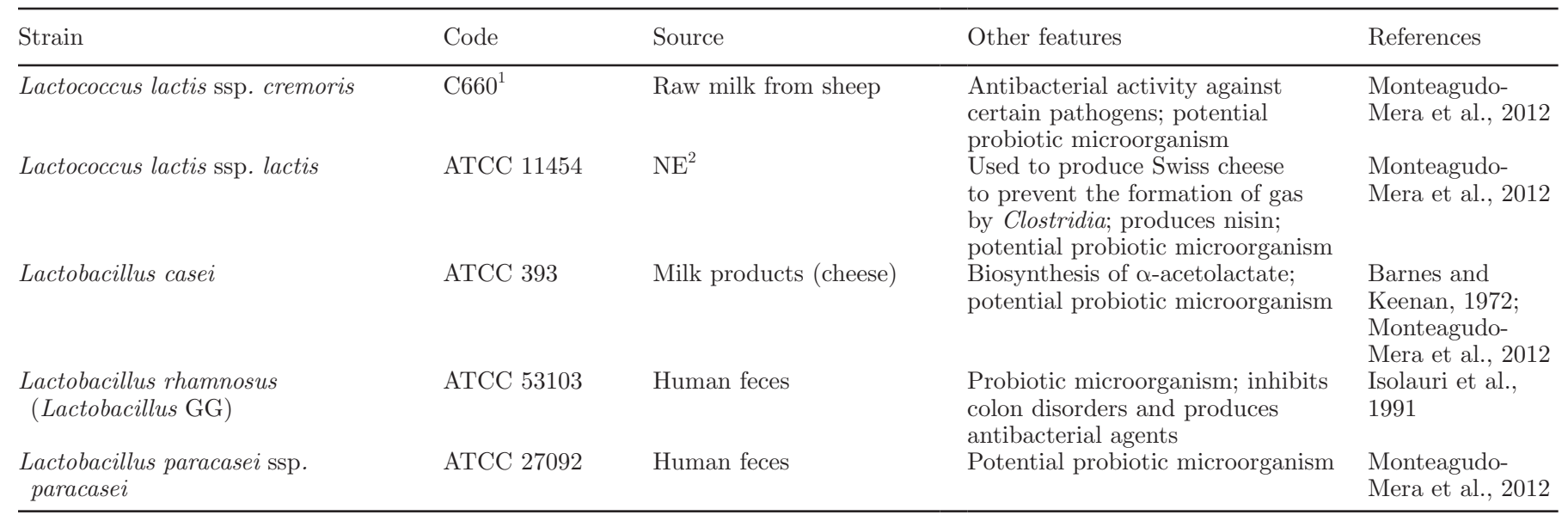

${ }^{1}$ Internal codes assigned in the Department of Hygiene and Food Technology Collection, University of Leon.

${ }^{2} \mathrm{NE}=$ nonspecific.

(LAB) and $540 \mathrm{~nm}$ (pathogenic strains). In all cases, $300 \mu \mathrm{L}$ of the above resuspension, adjusted to OD 1.0, were used to inoculate a flask containing $10 \mathrm{~mL}$ of TSB. Liquid cultures of LAB strains were incubated without shaking for $24 \mathrm{~h}$ and the pathogen strain cultures were incubated by shaking $(250 \mathrm{rpm})$ for $12 \mathrm{~h}$. To obtain the cell-free fermented broth, the cultures were centrifuged at $10,000 \times g$ for $5 \mathrm{~min}$ at room temperature, and these were combined with fresh medium to prevent the depletion of nutrients and used to check the growth capacity of the different pathogenic strains. The evaluation of the growth inhibition effect by the LAB fermented broth was carried out by incubation of $300 \mu \mathrm{L}$ (OD 1.0) of pathogenic strains in $2 \mathrm{~mL}$ of fresh medium (TSB)

Table 2. Potentially pathogenic strains used in this work

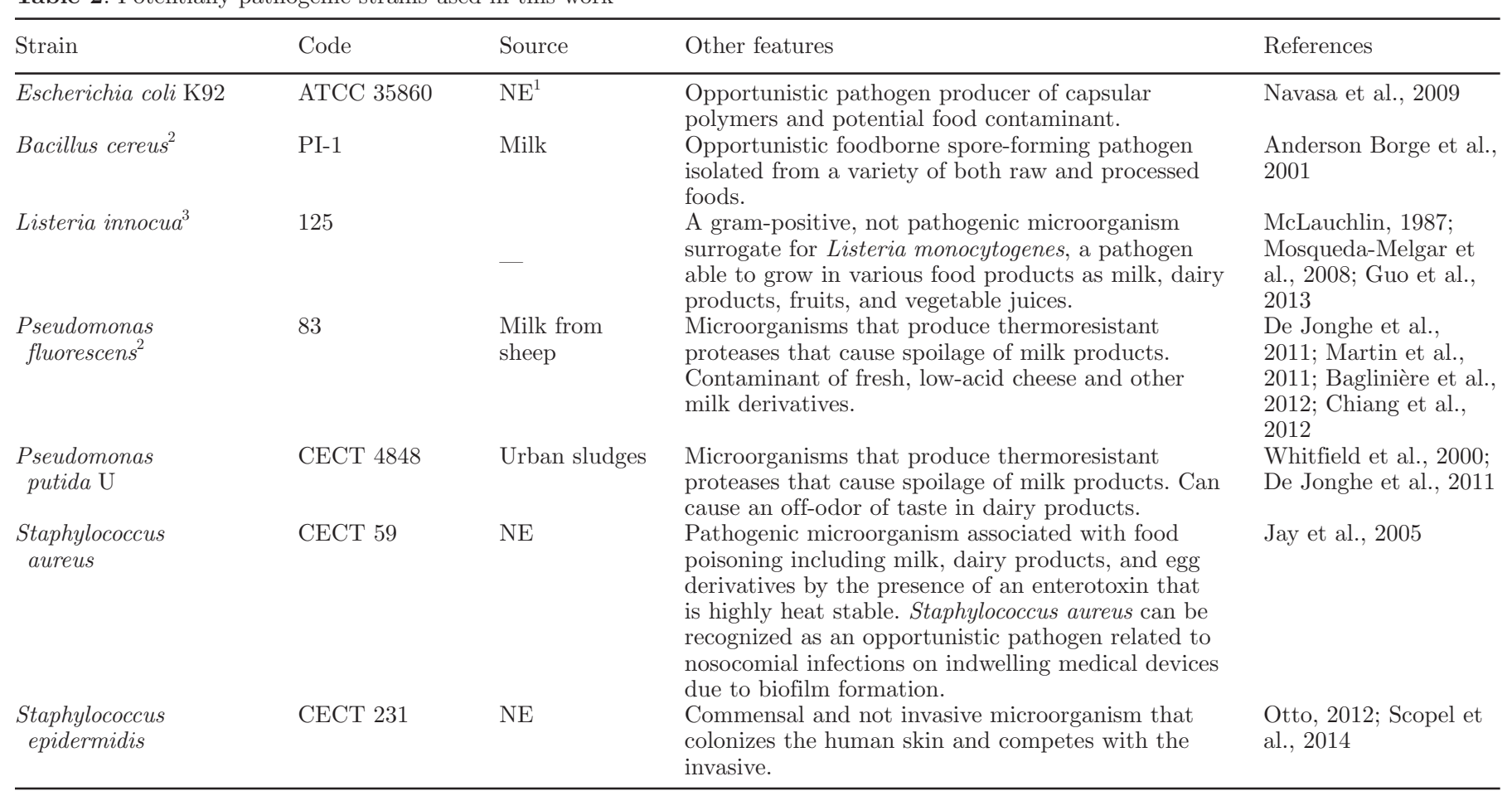

${ }^{1} \mathrm{NE}=$ nonspecific.

${ }^{2}$ From the Culture Collection Hannah Research Institute (CCM, Ayr, Scotland).

${ }^{3}$ From the Department of Hygiene and Food Technology Collection, University of León. 
with $1 \mathrm{~mL}$ of cell-free fermented LAB. Two controls of growth were carried out, one of them using $2 \mathrm{~mL}$ of fresh TSB and $1 \mathrm{~mL}$ of cell-free broth of the potentially pathogenic strains, and the other was performed using $3 \mathrm{~mL}$ of fresh medium (TSB).

The growth inhibition effect also was tested by bioassay using the methodology described by McGroarty et al. (1992) with some modifications. The cell-free fermented broths were obtained by centrifugation after different times of LAB incubation (from 0 to 24 $\mathrm{h}$, at intervals of 2 or $3 \mathrm{~h}$ ) and then were tested with the pathogenic strains. To prevent the broths from potentially losing a particular property, the assays were synchronized and the bacteria were cultured at different times so that no more than $5 \mathrm{~h}$ elapsed from collection to use in the bioassay; during this waiting time, the broths were stored in the refrigerator at $4^{\circ} \mathrm{C}$. We proceeded to cover plates; for this purpose $100 \mu \mathrm{L}$ (OD 1.0) of potentially pathogenic strains was added to $3 \mathrm{~mL}$ of TSA tempered in a bath at $42^{\circ} \mathrm{C}$ and then poured onto TSA plates annealed in an oven at $37^{\circ} \mathrm{C}$ and allowed to cool for $5 \mathrm{~min}$ in the refrigerator at $4^{\circ} \mathrm{C}$. Finally, $60 \mu \mathrm{L}$ of LAB broth or TSB (used as a control) was added to the wells performed on each plate. The plates were put into to the refrigerator for $60 \mathrm{~min}$ to allow the diffusion of the well content and then were incubated at an adequate temperature. After $12 \mathrm{~h}$, we checked the plates to see whether the LAB-fermented broths had any effect on the growth of the potentially pathogenic strains and, thus, corroborated the findings in the previous section.

The short-chain fatty acids (SCFA) released into the LAB broths were evaluated along with the bacterial growth time according to the procedure described by Zhao et al. (2006). The SCFA (ethanol, acetoin, acetic acid, propionic acid, 2,3-butanediol, butyric acid, and diacetyl) were identified on chromatograms by their specific retention times using a Perkin Elmer Autosystem XL GC equipped with a flame ionization detector (Perkin Elmer, Waltham, MA). A fused silica capillary column (TRB-FFAP, Teknokroma SL, Barcelona, Spain) coated with 1- $\mu$ m thick film was used. The column was $30 \mathrm{~cm}$ long and had an inner diameter of $0.53 \mathrm{~mm}$. Helium was supplied as the carrier gas at a pressure rate of $9.51 \times 10^{4} \mathrm{~Pa}$. The initial oven temperature was $130^{\circ} \mathrm{C}$ and was maintained for $3 \mathrm{~min}$. The temperature was then raised to $170^{\circ} \mathrm{C}$ at a rate of $40^{\circ} \mathrm{C} /$ min and held for $2.0 \mathrm{~min}$. The temperature of the flame ionization detector and injection port was $250^{\circ} \mathrm{C}$. The flow rates of hydrogen and air (used as makeup gases) were 50 and $500 \mathrm{~mL} / \mathrm{min}$, respectively. The injected sample volume for the GC analysis was $2 \mathrm{~mL}$. Volatile fatty acid standards were obtained from Sigma Aldrich (St. Louis, MO). To quantify the peak area in terms of concentration, the relative response factor was used, following the methodology described by Ranilla et al. (2001).

To check the effect of these SCFA on pathogenic bacteria growth, we added to the growth medium each fatty acid (ethanol, acetoin, acetic acid, propionic acid, 2,3-butanediol, butyric acid, and diacetyl) at (1) the maximal concentration and (2) a concentration 5-fold higher, in both cases using the levels of production registered in $\mathrm{LAB}$ as reference values. Moreover, to test if the inhibitory effect could be caused by the liberation of $\mathrm{H}_{2} \mathrm{O}_{2}$ during the growth of LAB, catalase $(1 \mathrm{mg} / \mathrm{mL})$ was added to the broths to prevent this effect in accordance with the methodology described by Yang et al. (2012). In addition, pH measurements were taken for all broths obtained and in all cases and times assayed were near to neutrality.

\section{Determining the Effect of $L A B$ on Pathogenic Bacterial Adhesion}

Adhesion assays were performed essentially according to the method of Nagant et al. (2010). Briefly, LAB and potentially pathogenic strains were grown in TSA slant tubes at the appropriate temperature for 24 and 12 h, respectively (Monteagudo-Mera et al., 2011). Flasks of TSB were then inoculated with $50 \mu \mathrm{L}$ at OD 1.0 and cells were obtained from the exponential phase of growth. The broths were recovered after pelleting of cells by centrifugation. The 96 -well microtiter plates (Deltalab, Barcelona, Spain) were filled with $120 \mu \mathrm{L}$ of cell-free broth of LAB strains and $60 \mu \mathrm{L}$ of TSB, and others with $120 \mu \mathrm{L}$ of cell-free broth of potentially pathogenic strains and $60 \mu \mathrm{L}$ of TSB. All wells were inoculated with $20 \mu \mathrm{L}$ at OD 2.0 with cells of each potentially pathogenic strain. The plates were incubated for $12 \mathrm{~h}$ at $37^{\circ} \mathrm{C}$, except the Pseudomonas strains which were incubated at $30^{\circ} \mathrm{C}$. To establish the positive controls, wells were filled with $180 \mu \mathrm{L}$ of TSB and $20 \mu \mathrm{L}$ at OD 2.0 of potentially pathogenic strains; to establish the blanks, some wells were filled with $200 \mu \mathrm{L}$ of sterile TSB. Controls of these assays were carried out in the presence of cell-free broths boiled for $5 \mathrm{~min}$ at $100^{\circ} \mathrm{C}$ to test the possible inhibition caused by thermosensitive agents. To evaluate the adhesion we used the method of Kubota et al. (2008); after removal of the broths from the wells, these were washed 3 times with $200 \mu \mathrm{L}$ of PBS. Adherent cells were then stained with $125 \mu \mathrm{L}$ of crystal violet solution $(0.2 \% \mathrm{wt} / \mathrm{vol})$. After $30 \mathrm{~min}$, the excess of crystal violet was removed and the wells were washed twice with $200 \mu \mathrm{L}$ of PBS. The dye was dissolved with absolute ethanol and the plate was read on the Anthos 2020 (Biochrom, Cambridge, UK) at 540 $\mathrm{nm}$. The results were expressed as an increasing of the 
absorbance measured at $540 \mathrm{~nm}$. Each experimental condition was evaluated in quadruplicate. To check the inhibitory effect to the SCFA on adhesion of potentially pathogenic strains we added these compounds to the adhesion assay at a concentration that was calculated as the average of all the fatty acid LAB production values and also at a concentration 5 -fold higher.

\section{Statistical Analysis}

The results are presented as means \pm standard error of the mean. Significant differences between means were calculated with Student's $t$-test; $P$-values of 0.05 or less were considered statistically significant.

\section{RESULTS AND DISCUSSION}

In this work we studied the competition between 5 potentially probiotic LAB strains previously characterized in our laboratory and 7 potentially pathogenic and food-contaminating strains. Lactococcus lactis C660 LAB was selected from a previous work carried out in our laboratory at the University of León (MonteagudoMera et al., 2011) based on its antimicrobial activity, whereas the rest were obtained from the ATCC and were selected based on their origin (human or milk), potential as a probiotic, or antimicrobial properties (Monteagudo-Mera et al., 2011). Indeed, one of the bacteria obtained from the ATCC corresponds to the strain Lactobacillus rhamnosus GG (ATCC 53103), one of the most researched in the world because of its potential probiotic properties (Gorbach and Goldin, 1989).

\section{Effect of LAB Culture Broths on the Growth Pathogenic Strains}

The microbial world has a wide variety of competitors, and a large range of mechanisms may be responsible for the appearance of dominant microbial populations. Because food resources are key in microbial competition, once the collection time of the bacterial culture broths was established we studied if the LAB fermented broths had any effect over the proliferation of the pathogenic strains. Preliminary results from our laboratory showed that the broth form Lc. lactis ATCC 11454 caused a clear inhibition of $B$. cereus growth, but no clear effect was seen for most of the other strains tested (Monteagudo-Mera et al., 2011). We then evaluated the effect of LAB fermented broths on the growth of pathogenic bacteria and by bioassay (see Materials and Methods) and we observed that E. coli K92, Ls. innocua, P. fluorescens, Staph. aureus, and Staph. epidermidis (but not $P$. putida) were also affected (Table 3 and Figure 1). The inhibitory effect study revealed that, as Figure 1A shows, the antibacterial broth effect of Lc. lactis C660 increased at the end of the $E$. coli K92 growth. However, in the case of P. fluorescens using Lc. lactis broth (Figure 1B), P. fluorescens and Staph. aureus using L. casei 393 broth (Figure 1D and E), and E. coli K92 and Ls. innocua using Lb. rhamnosus broth (Figure $1 \mathrm{G}$ and $\mathrm{H}$ ), the inhibitory effect occurred during the exponential phase of growth. It is worth remarking on the inhibitory effect caused on Staph. epidermidis by all the lactic broth from Lc. lactis C660 (Figure 1C), Lc. lactis 11454 (Table 3), Lb. casei 393 (Figure 1F), and Lb. rhamnosus (Figure 1I). In all these cases we observed that the growth was totally inhibited from the early stages of growth (Figures 1C, $\mathrm{F}$, and I).

In line with our results, different authors have observed the effect caused on the growth of different pathogenic bacteria of culture medium in which LAB have grown (Drago et al., 1997; Olivares et al., 2006; López-Brea et al., 2008; Jara et al., 2011), although in some cases the effect could be observed only if these broths were previously concentrated (López-Brea et al., 2008) or at specific pH (Yang et al., 2012). Thus, Yang et al. (2012) described that Lc. lactis is only able to inhibit E. coli growth when the $\mathrm{pH}$ of the broth was not adjusted to $\mathrm{pH} 7$ and the effect disappeared after adjusting the $\mathrm{pH}$. Nevertheless, in our work Lc. lactis C660 is also able to inhibit E. coli K92 growth (Figure $1 \mathrm{~A}$ ) even when the culture broth is a $\mathrm{pH}$ near to neutral-

Table 3. Results of the effect of lactic acid bacteria (LAB) culture broths on the growth of potentially pathogenic strains ${ }^{1}$

\begin{tabular}{|c|c|c|c|c|c|c|c|}
\hline Strain $(\%)$ & $\begin{array}{c}\text { Escherichia coli } \\
\text { K92 }\end{array}$ & $\begin{array}{l}\text { Bacillus } \\
\text { cereus }\end{array}$ & $\begin{array}{l}\text { Listeria } \\
\text { innocua }\end{array}$ & $\begin{array}{l}\text { Pseudomonas } \\
\text { fluorescens }\end{array}$ & $\begin{array}{l}\text { Pseudomonas } \\
\text { putida }\end{array}$ & $\begin{array}{c}\text { Staphylococcus } \\
\text { aureus }\end{array}$ & $\begin{array}{c}\text { Staphylococcus } \\
\text { epidermidis }\end{array}$ \\
\hline Lactococcus lactis C660 & 31 & $-^{2}$ & - & 19 & - & - & 76 \\
\hline L. lactis ATCC 11454 & - & - & - & - & - & - & 90 \\
\hline Lactobacillus paracasei & - & - & - & - & - & - & - \\
\hline Lactobacillus rhamnosus & 12 & - & 28 & - & - & - & 76 \\
\hline
\end{tabular}

${ }^{1}$ Percent inhibition is the difference between the optical density at the point of maximal inhibition by the LAB broth and control thereof cultured in trypticase soy broth.

${ }^{2}$ Nondetectable inhibition effect of growth. 


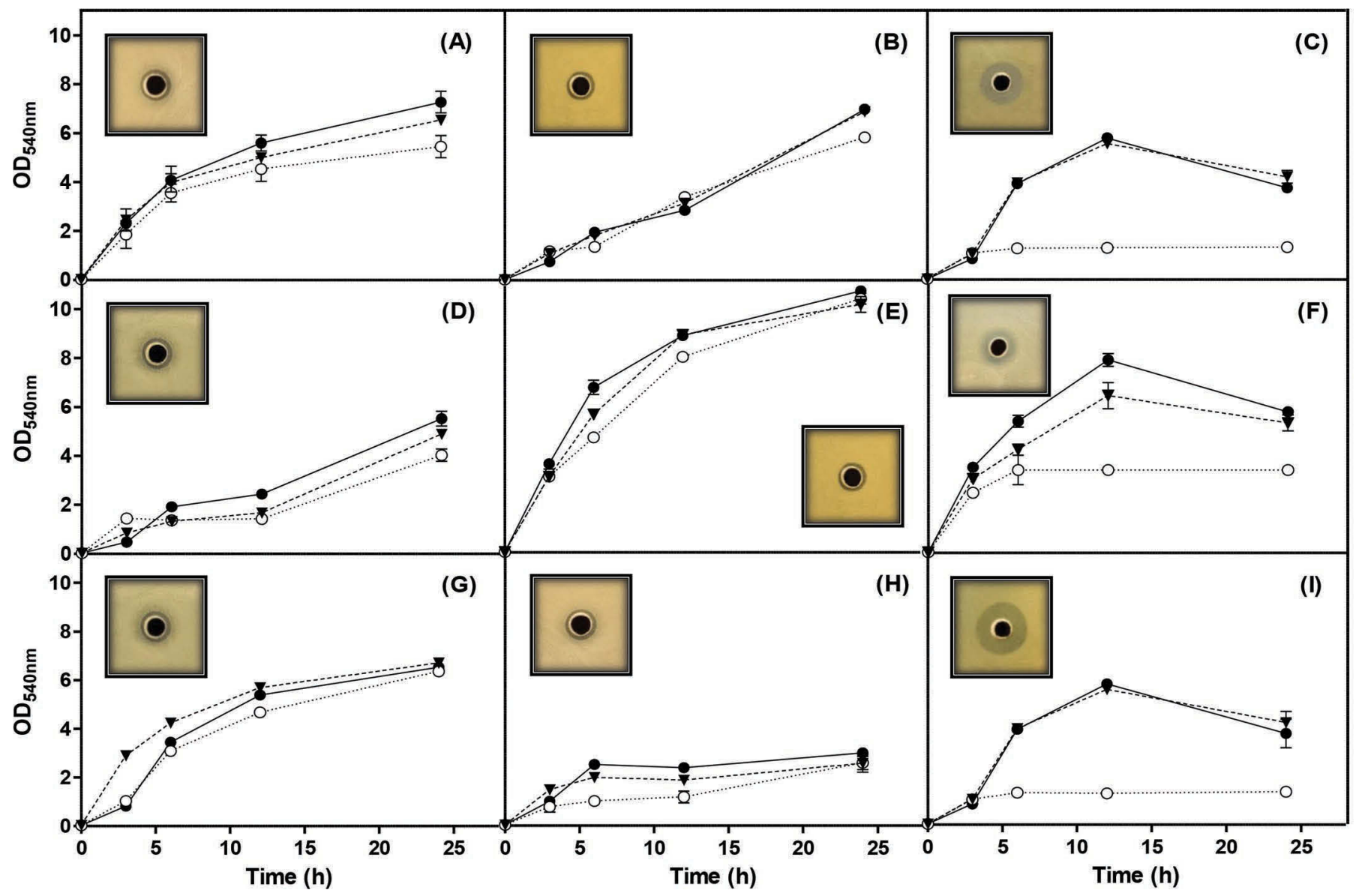

Figure 1. Growth curves and bioassays (maximal inhibition time) of Escherichia coli K92 (A and G), Pseudomonas fluorescens (B and D), Staphylococcus epidermidis (C, F, and I), Staphylococcus aureus (E), and Listeria innocua (H) in the presence of (-) trypticase soy broth, ( $\mathbf{\nabla})$ their own culture broth, and $(\mathrm{O})$ 24-h fermented broth from Lactococcus lactis C660 (A-C); Lactobacillus casei 393 (D-F), and Lactobacillus rhamnosus $(\mathrm{G}-\mathrm{I}) . \mathrm{OD}_{540 \mathrm{~nm}}=$ optical density at $540 \mathrm{~nm}$. The error bars indicate the standard deviation. Color version available online.

ity (see Materials and Methods). Furthermore, (Enan et al., 2013) described that broths of different strains of Lc. lactis are able to inhibit the growth of Staph. aureus. However, in our assay conditions, we observed that neither Lc. lactis C660 nor Lc. lactis ATCC 11454 produced any effect on this pathogenic strain (Table 3 ).

With regard to the genus Lactobacillus, similar to results published by Yang et al. (2012), Lb. rhamnosus broth was able to inhibit the growth of Ls. innocua mainly between 5 and $12 \mathrm{~h}$ (Figure 1H). Previous results (Silva et al., 1987) also revealed that this broth bacterium was able to inhibit the growth of $E$. coli B-44, but not E. coli O157:H7. In our case, E. coli K92 growth was inhibited by $L b$. rhamnosus broth (Figure $1 \mathrm{G})$. These findings corroborate those related by other authors (Johnson-Henry et al., 2008) with respect to the different behaviors that probiotics, such as $L b$. rhamnosus, have on different strains of the same bacterial species. This variability is also observed in the
Lactobacillus genus; Abriouel et al., (2012) describes how the broth of Lactobacillus pentosus is able to inhibit the growth of B. cereus, Staph. aureus, and $P$. fluorescens, whereas our results reveal that broth from $L b$. casei is able to cause an inhibitory effect on the growth of Staph. aureus and P. fluorescens (Figure 1D and $\mathrm{E}$ ) but not on B. cereus (Table 3). All of these cases indicate that 2 bacteria do not have the same behavior, and, even within the same species, different strains may have quite different and sometimes contrasting effects. Therefore, to establish the antimicrobial behavior of LAB it is necessary to study each directly against specific pathogen strains.

Lactic acid bacteria exert their antibacterial activity through the production of different factors, such as hydrogen peroxide, lactic acid, media acidification, SCFA, and specific antibacterial compounds such as antibiotics or bacteriocins, that have been identified in the culture media of several LAB (Drago et al., 


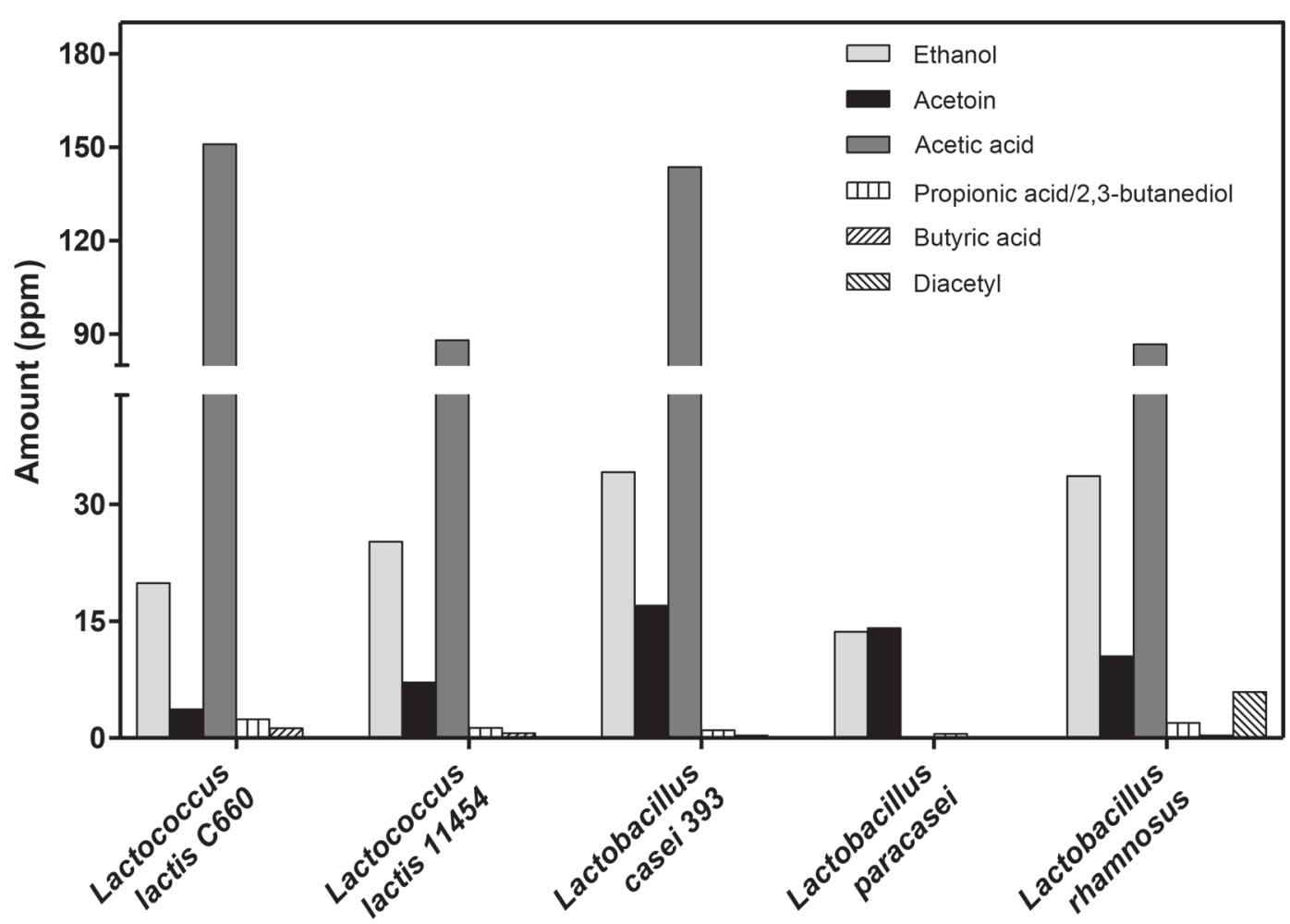

Figure 2. Maximal production of short-chain fatty acids by lactic acid bacteria. Propionic acid and 2,3-butanediol showed the same retention time using this methodology.

1997; Monteagudo-Mera et al., 2011, 2012). Although the precise mechanisms by which the broths from our strains inhibit growth of pathogens are not fully understood at present, the fact that all the broths tested in our experiments exhibited a $\mathrm{pH}$ near neutrality (data not shown) indicate that the production of lactic acid is not enough to cause the pathogen viability inhibition observed. Hydrogen peroxide also does not appear to be involved in the bacterial activity, as the addition of catalase (see Materials and Methods) did not modify the bactericidal effect (data not shown). The SCFA have been associated as determinant factors in the inhibition of growth caused by different LAB (Piard and Desmazeaud, 1991; Salminen et al., 2004; Olvera-García et al., 2015). The SFCA produced by the $\mathrm{LAB}$ analyzed in the present work were identified and quantified using GC (see Materials and Methods). As shown in Figure 2, except in the case of acetic acid (between $87 \mathrm{mg} / \mathrm{L}$ to $L b$. rhamnosus and $150 \mathrm{mg} / \mathrm{L}$ to $L c$. lactis $\mathrm{C660)}$ ), the production of the other compounds was very low (not exceeding $32 \mathrm{mg} / \mathrm{L}$ in the case of ethanol to $L b$. rhamnosus; $33 \mathrm{mg} / \mathrm{L}$ of acetoin to $L b$. casei $393 ; 2.4 \mathrm{mg} / \mathrm{L}$ of propionic acid/2,3-butanediol to Lc. lactis $\mathrm{C} 660 ; 1.27 \mathrm{mg} / \mathrm{L}$ of butyric acid to Lc. lactis C660; and $6 \mathrm{mg} / \mathrm{L}$ of diacetyl to Lb. rhamnosus). These maximal concentrations (Figure 2) and those 5-fold higher of each fatty acid were tested to evaluate their effect on the growth of the pathogenic bacteria tested. No inhibitory bacterial growth was detected even when a fatty acid concentration 5-fold higher was used (data not shown). These results indicate that the inhibitory growth effect obtained by the addition of different LAB broths (Figure 1) is not a consequence of the presence in the media of these SCFA.

\section{Effect of LAB Culture Broths on the Adhesion of Potentially Pathogenic Strains}

The modification in adhesion and biofilm formation caused by binding and displacement of pathogenic microorganisms by LAB led to the conclusion that it is most likely due to steric hindrance or related to mechanisms other than those involving competition for the specific binding sites (Tuomola et al., 1999; Larsen et al., 2007). Furthermore, the participation of any antibacterial lipophilic factor (Liévin-Le Moal et al., 2002), proteinaceous factor (Teneberg et al., 2004), and antimicrobial compounds of uncertain composition that prevents adherence (Coconnier et al., 2000) has been reported.

Our previous results had reported that the LAB are capable of adhering and forming biofilm in both abiotic 
and biotic surfaces, such as Caco-2 cells, and, in the case of Lc. lactis C660, with a high capacity (MonteagudoMera et al., 2012). Therefore, through competition for the same binding sites, these LAB can have the ability to impede the adhesion and biofilm formation of pathogenic bacteria. In the previous section we observed that cell-free fermented broths are able to inhibit the growth of pathogenic bacteria, and it is possible that they may also affect the ability of adhesion and, consequently, the biofilm formation of pathogenic bacteria. As observed in Figure 3, our results reveal that the presence of fermented broth from 4 LAB (Lc. lactis C660, Lc. lactis 11454, Lb. paracasei, and Lb. rhamnosus) reduced the E. coli K92 adhesion capacity, although to different degrees (from $15 \%$ in the case of $L b$. rhamnosus to $40 \%$ for Lc. lactis C660). Only the addition of broth from $L c$. casei showed a significant increase in adhesion formation (up to 185\%). Several investigators have reported results on the effect of diverse $\mathrm{LAB}$ on the adhesion of different $E$. coli strains; thus, it has been described that some Lactobacillus do not modify the adhesion of E. coli (Gagnon et al., 2004; Collado et al., 2005), whereas probiotic strains are capable of inhibiting bacterial attachment, as in our case (Collado et al., 2005; Johnson-Henry et al., 2007; Larsen et al., 2007; Candela et al., 2008). Furthermore, our data on increased adhesion caused by $L b$. casei agree with the results obtained by Parassol et al., (2005) with E. coli using the enteropathogenic strain E2348/69. The cellular growth of $B$. cereus was inhibited by Lc. lactis ATCC 11454 broth (Monteagudo-Mera et al., 2011); we showed a decrease of adhesion by this bacterium in the presence of both the Lc. lactis strains tested and $L b$. paracasei broths (Figure 3). This antiadhesion effect was similar to that reported by (Ksontini et al., 2013). However, broth from Lb. rhamnosus and Lb. casei 393 caused a B. cereus attachment increase (10 and 70\%, respectively). Listeria innocua adhesion inhibition was observed in the presence of $L b$. paracasei broth, but the greatest inhibitory effect on adhesion (up to 80\%) of all the cases tested was registered when this bacterium was incubated in the presence of Lc. lactis 11454 broth (Figure 3). However, broths from the other LAB slightly increased the binding of this microorganism. With regard to the 2 Pseudomonas species selected in our study, we observed that, except for the slight adhesion inhibition showed by $L b$. rhamnosus broth against P. putida, no antiadhesion effect was achieved (Figure $3)$. In contrast, bacterial attachment increase was registered in the presence Lc. lactis C660 and Lb. casei 393 broths for the 2 Pseudomonas tested, Lc. lactis 11454, and $L b$. rhamnosus broths for P. fluorescens. All LAB broths used in our work caused an adhesion stimulation in the 2 Staphylococcus species tested (Staph. aureus and Staph. epidermidis). As Figure 3 shows, bacterial attachment increased between 20 and $300 \%$ for Staph. aureus (with Lc. casei broth) and for Staph. epidermidis (with $L b$. rhamnosus broth), respectively.

The results summarized in Figure 3 confirm that the effect caused by the different LAB assayed is also brothand species-specific and reveal that the broth from LAB tested in this work can be used as functional bioactive compounds to regulate the adhesion and biofilm synthesis and ultimately lead to preventing the food and clinical contamination and colonization of E. coli K92, B. cereus, and Ls. innocua. Nevertheless, it should be noted that the broth from LAB stimulate the biofilm formation of the potentially pathogenic P. putida, $P$. fluorescens, Staph. aureus, and Staph. epidermidis. In spite of this, the fact that the LAB broths stimulated Staph. epidermidis adhesion can be useful for promoting the colonization of this bacterium when it behaves as a mutualistic microorganism, such as in balancing skin microbiota (Otto, 2009; Christensen and Brüggemann, 2014; Morán et al., 2014). All these results allow us to conclude that the adhesion changes of potentially pathogenic bacteria (positive or negative) registered in the presence of cell-free probiotic fermented broths are caused by a product released into the medium during the growth of LAB, and this product is heat-resistant because no differences have been achieved (data not shows) when the LAB broths were boiled (see Materials and Methods). In this regard, considerable evidence supports the action of $\mathrm{H}_{2} \mathrm{O}_{2}$ produced by probiotics on the changes in the structure and viability of the biofilms (Saunders et al., 2007). Moreover, the broth acidification or production of organic acids can affect biofilm genesis (Coconnier et al., 2000). However, our LAB-fermented broths did not show significant $\mathrm{pH}$ changes after bacterial growth, and the adhesion was not modified when we prevented the $\mathrm{H}_{2} \mathrm{O}_{2}$ presence by the addition of catalase (data not shown).

Evaluation of the effect of SFCA produced by LAB was carried out only with those pathogenic bacteria that showed a significant adhesion inhibition $(E$. coli K92, B. cereus, and Ls. innocua) when different LAB broths were added (Figure 3). The results obtained are summarized in Figure 4. Although the tested fatty acids may have individual effects on pathogenic bacteria, our aim was to correlate the bacterial adhesion inhibitory effect shown by the LAB broths (Figure 3) with the production of SFCA by these bacteria (Figure 2). The addition of acetic acid to the adhesion assay (see Materials and Methods) did not modify the bacterial attachment (positive or negative) on the 3 pathogenic strains tested (Figure 4). This result indicates that acetic acid is not responsible of the inhibitory effect on pathogenic bacteria adhesion (see Figure 3). Butyric 


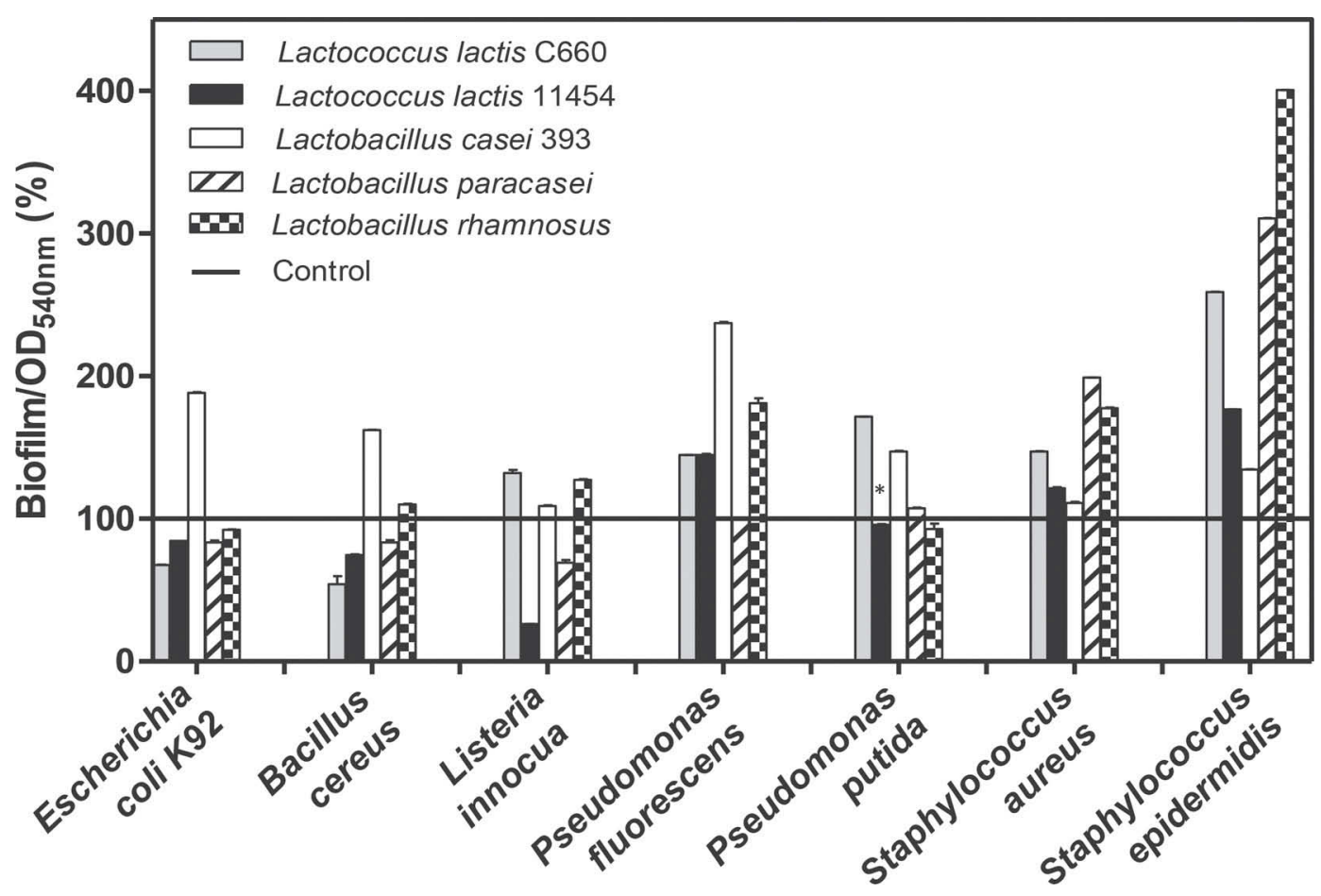

Figure 3. Effect of the broths obtained from the lactic acid bacteria (LAB) on the bacterial adhesion developed by the different pathogen strains. Values are expressed as the percentage biofilm of bacteria in presence of LAB broth treatment, compared with the control (black line), which does not contain broth of LAB, expressed as means \pm SEM of the 3 assays in triplicate. An asterisk $(*)$ indicates no significant differences $(P<0.05)$ with respect to control. $\mathrm{OD}_{540 \mathrm{~nm}}=$ optical density at $540 \mathrm{~nm}$.

acid and acetoin, which are produced by Lc. lactis C660, Lc. lactis 11454, and Lb. rhamnosus, but not by Lb. paracasei (Figure 2), modified the adhesion of E. coli K92 and Ls. innocua (Figure 4). However, these fatty acids would not be responsible of the inhibition of adhesion of E. coli K92 and Ls. innocua (see Figure 3), which is also supported by the fact that $L b$. paracasei, lacking production of these fatty acids, also shows a significant inhibitory adhesion effect. Ethanol and propionic acid or 2,3-butanediol produced by all LAB, except Lc. $c a$ sei 393, did not show inhibitory adhesion effect of $B$. cereus (Figure 4) when were tested at 30 and $2 \mathrm{mg} / \mathrm{L}$, respectively (concentrations produced by the LAB, see Figure 2). Although we observed an inhibitory adhesion effect $(15 \%)$ when the concentration was 5 -fold higher (Figure 4), these results indicate that inhibition of $B$. cereus adhesion observed in Figure 3 caused by the different broths is not a direct consequence of the presence of these fatty acids in the LAB broths. Ethanol, propionic acid, and 2,3-butanediol also showed inhibitory effects of E. coli K92 and Ls. innocua adhesion (Figure $4)$; the presence of ethanol caused a decrease of the $E$. coli K92 (25\%) and Ls. innocua (70\%) adhesion. With propionic acid and 2,3-butanediol, the adhesion inhibition reached values of $10 \%$ to E. coli K92 and between 22 and $40 \%$ to Ls. innocua at the SFCA concentrations produced by LAB (Figure 2). Analyzing these results and those obtained in the study of the effect of the addition of different culture broths together (Figure 3), it can be concluded that $E$. coli K92 inhibition was due to the presence of these compounds. Whereas the lack of inhibition of Ls. innocua by Lc. lactis C660, Lb. casei 393 , and $L b$. rhamnosus broths led us to conclude that the adhesion inhibition of this bacteria caused by $L c$. lactis 11454 and $L b$. paracasei broths is not caused by these fatty acids.

Other bioactive substances such as bacteriocins, biosurfactants, and other related molecules have been associated with adhesion and biofilm genesis modification (Jeon et al., 2011). Indeed, in some cases they have received considerable attention and the target of their action has begun to be known. This is true of Lb. rhamnosus, a prototypical probiotic whose production of bacteriocins produces inhibitory activity on the biosynthesis of exopolysaccharide of the pathogenic bacteria (Jeon et al., 2011). It is also known that the biosynthesis of glucans plays a crucial role in biofilm formation (Koo et al., 2013), and several LAB are able to regulate the expression of genes encoding glucosyltransferases through still unknown mechanisms. Tahmourespour et al. (2011) described how the expression of $g t f B / C$ genes related to glucan from Streptococcus mutants 


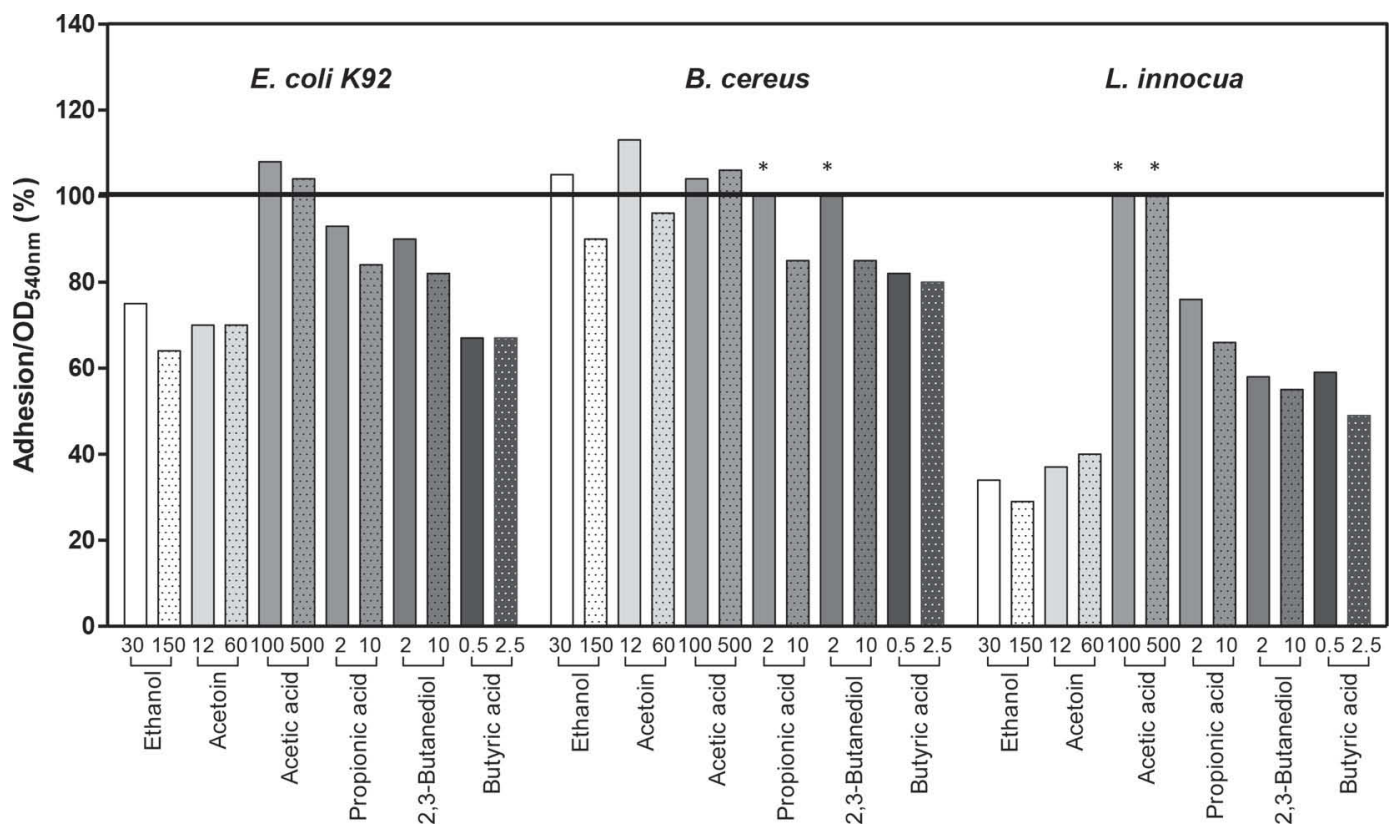

Figure 4. Effect of the short-chain fatty acids (SCFA) on the bacterial adhesion (Escherichia coli K92, Bacillus cereus, Listeria innocua). Values are expressed as the percentage of bacteria adhesion in the presence of SCFA, compared with the control (black line), which does not contain any fatty acid. Values are expressed as means \pm SEM of the 3 assays in triplicate. An asterisk $\left(^{*}\right)$ indicates no significant differences $(P$ $<0.05)$ with respect to control. $\mathrm{OD}_{540 \mathrm{~nm}}=$ optical density at $540 \mathrm{~nm}$.

are modified for the product released by Lactobacillus fermentum. In other cases it has been reported that the exopolysaccharides released from LAB are able to decrease pathogenic biofilm formation by affecting the genes related to curli production $(c r l, c s g A$, and $\operatorname{cgs} B$ genes) and chemotaxis (che $Y$ gene; Kim et al., 2009). It is clear that $\mathrm{LAB}$ produce specific molecules that, when released into the medium, modify the viability, adhesion, and biofilm synthesis capacity of other microorganisms. As previously (Viswanathan et al., 2009) noted, we have a new alternative for the treatment and prevention of the effects caused by potentially pathogenic bacteria capable of developing antibiotic resistance. The use of LAB can be an adequate or complementary antibiotic strategy to prevent the growth and proliferation of undesired bacteria and represent a growing area of current biotechnological research (food and clinical areas). Further analysis of the factors directly involved in these effects would allow the direct use of these molecules in preventing the harmful effects these bacteria cause to health to be studied. More in this regard is currently in progress.

\section{ACKNOWLEDGMENTS}

This study was financially supported by La Junta de Castilla y León, Spain (ref. LE283U14).

\section{REFERENCES}

Abad, C. L., and N. Safdar. 2009. The role of Lactobacillus probiotics in the treatment or prevention of urogenital infections-A systematic review. J. Chemother. 21:243-252.

Abriouel, H., N. Benomar, A. Cobo, N. Caballero, M. A. FernándezFuentes, R. Pérez-Pulido, and A. Gálvez. 2012. Characterization of lactic acid bacteria from naturally-fermented Manzanilla Aloreña green table olives. Food Microbiol. 32:308-316.

Ahrné, S., S. Nobaek, B. Jeppsson, I. Adlerberth, A. E. Wold, and G. Molin. 1998. The normal Lactobacillus flora of healthy human rectal and oral mucosa. J. Appl. Microbiol. 85:88-94.

Anderson Borge, G. I., M. Skeie, T. Sørhaug, T. Langsrud, and P. E. Granum. 2001. Growth and toxin profiles of Bacillus cereus isolated from different food sources. Int. J. Food Microbiol. 69:237-246.

Andreu, A., A. E. Stapleton, C. L. Fennell, S. L. Hillier, and W. E. Stamm. 1995. Hemagglutination, adherence, and surface properties of vaginal Lactobacillus species. J. Infect. Dis. 171:1237-1243.

Baglinière, F., G. Tanguy, J. Jardin, A. Matéos, V. Briard, F. Rousseau, B. Robert, E. Beaucher, G. Humbert, A. Dary, J. L. Gaillard, C. Amiel, and F. Gaucheron. 2012. Quantitative and qualitative variability of the caseinolytic potential of different strains of Pseudomonas fluorescens: Implications for the stability of casein micelles of UHT milks during their storage. Food Chem. 135:25932603.

Baron, F., M. F. Cochet, N. Grosset, M. N. Madec, R. Briandet, S. Dessaigne, S. Chevalier, M. Gautier, and S. Jan. 2007. Isolation and characterization of a psychrotolerant toxin producer, Bacillus weihenstephanensis, in liquid egg products. J. Food Prot. 70:27822791.

Barnes, A. L., and T. W. Keenan. 1972. Biosynthesis of $\alpha$-acetolactate and its conversion to diacetyl and acetoin in cell-free extracts of Lactobacillus casei. Can. J. Microbiol. 18:479-485.

Cadieux, P., J. Burton, G. Gardiner, I. Braunstein, A. W. Bruce, C. Y. Kang, and G. Reid. 2002. Lactobacillus strains and vaginal ecology. JAMA 287:1940-1941. 
Caglar, E., S. K. Cildir, S. Ergeneli, N. Sandalli, and S. Twetman. 2006. Salivary mutans streptococci and lactobacilli levels after ingestion of the probiotic bacterium Lactobacillus reuteri ATCC 55730 by straws or tablets. Acta Odontol. Scand. 64:314-318.

Candela, M., F. Perna, P. Carnevali, B. Vitali, R. Ciati, P. Gionchetti, F. Rizzello, M. Campieri, and P. Brigidi. 2008. Interaction of probiotic Lactobacillus and Bifidobacterium strains with human intestinal epithelial cells: Adhesion properties, competition against enteropathogens and modulation of IL-8 production. Int. J. Food Microbiol. 125:286-292.

Chiang, Y.-C., H.-Y. Tsen, H.-Y. Chen, Y.-H. Chang, C.-K. Lin, C.Y. Chen, and W.-Y. Pai. 2012. Multiplex PCR and a chromogenic DNA macroarray for the detection of Listeria monocytogens, Staphylococcus aureus, Streptococcus agalactiae, Enterobacter sakazakii, Escherichia coli O157:H7, Vibrio parahaemolyticus, Salmonella spp. and Pseudomonas fluorescens in milk and meat samples. J. Microbiol. Methods 88:110-116.

Christensen, G. J. M., and H. Brüggemann. 2014. Bacterial skin commensals and their role as host guardians. Benef. Microbes 5:201215.

Coconnier, M. H., V. Liévin, M. Lorrot, and A. L. Servin. 2000. Antagonistic activity of Lactobacillus acidophilus LB against intracellular Salmonella enterica serovar Typhimurium infecting human enterocyte-like Caco-2/TC-7 cells. Appl. Environ. Microbiol. 66:1152-1157.

Collado, M. C., M. Gueimonde, M. Hernández, Y. Sanz, and S. Salminen. 2005. Adhesion of selected Bifidobacterium strains to human intestinal mucus and the role of adhesion in enteropathogen exclusion. J. Food Prot. 68:2672-2678.

De Jonghe, V., A. Coorevits, K. Van Hoorde, W. Messens, A. Van Landschoot, P. De Vos, and M. Heyndrickx. 2011. Influence of storage conditions on the growth of Pseudomonas species in refrigerated raw milk. Appl. Environ. Microbiol. 77:460-470.

Drago, L., M. R. Gismondo, A. Lombardi, C. de Haën, and L. Gozzini. 1997. Inhibition of in vitro growth of enteropathogens by new Lactobacillus isolates of human intestinal origin. FEMS Microbiol. Lett. 153:455-463.

Enan, G., S. Abdel-Shafi, S. Ouda, and S. Negm. 2013. Novel antibacterial activity of Lactococcus lactis subspecies lactis z11 isolated from zabady. Int. J. Biomed. Sci. 9:174-180.

Fuller, R. 1989. Probiotics in man and animals. J. Appl. Bacteriol. $66: 365-378$.

Gagnon, M., E. E. Kheadr, G. Le Blay, and I. Fliss. 2004. In vitro inhibition of Escherichia coli O157:H7 by bifidobacterial strains of human origin. Int. J. Food Microbiol. 92:69-78.

Gill, H. S., Q. Shu, H. Lin, K. J. Rutherfurd, and M. L. Cross. 2001. Protection against translocating Salmonella typhimurium infection in mice by feeding the immuno-enhancing probiotic Lactobacillus rhamnosus strain HN001. Med. Microbiol. Immunol. (Berl.) 190:97-104.

Gorbach, S. L., and B. R. Goldin. 1989. Lactobacillus strains and methods of selection. Patent no. US4839281 A.

Guo, M., T. Z. Jin, O. J. Scullen, and C. H. Sommers. 2013. Effects of antimicrobial coatings and cryogenic freezing on survival and growth of Listeria innocua on frozen ready-to-eat shrimp during thawing. J. Food Sci. 78:M1195-M1200.

Guo, X., D. Li, W. Lu, X. Piao, and X. Chen. 2006. Screening of Bacillus strains as potential probiotics and subsequent confirmation of the in vivo effectiveness of Bacillus subtilis MA139 in pigs. Antonie Van Leewenhoek 90:139-146.

Isolauri, E., T. Rautanen, M. Juntunen, P. Sillanaukee, and T. Koivula. 1991. A human Lactobacillus strain (Lactobacillus casei sp strain GG) promotes recovery from acute diarrhea in children. Pediatrics 88:90-97.

Iwase, T., Y. Uehara, H. Shinji, A. Tajima, H. Seo, K. Takada, T. Agata, and Y. Mizunoe. 2010. Staphylococcus epidermidis Esp inhibits Staphylococcus aureus biofilm formation and nasal colonization. Nature 465:346-349.

Jara, S., M. Sánchez, R. Vera, J. Cofré, and E. Castro. 2011. The inhibitory activity of Lactobacillus spp. isolated from breast milk on gastrointestinal pathogenic bacteria of nosocomial origin. Anaerobe 17:474-477.

Jay, J. M., M. J. Loessner, and D. A. Golden. 2005. Modern Food Microbiology. 7th. ed, Food Science Text Series. Springer Science + Business Media Inc., New York, NY.

Jeon, J.-G., P. L. Rosalen, M. L. Falsetta, and H. Koo. 2011. Natural products in caries research: Current (limited) knowledge, challenges and future perspective. Caries Res. 45:243-263.

Johnson-Henry, K. C., K. A. Donato, G. Shen-Tu, M. Gordanpour, and P. M. Sherman. 2008. Lactobacillus rhamnosus strain GG prevents enterohemorrhagic Escherichia coli O157:H7-induced changes in epithelial barrier function. Infect. Immun. 76:1340-1348.

Johnson-Henry, K. C., K. E. Hagen, M. Gordonpour, T. A. Tompkins, and P. M. Sherman. 2007. Surface-layer protein extracts from Lactobacillus helveticus inhibit enterohaemorrhagic Escherichia coli O157:H7 adhesion to epithelial cells. Cell. Microbiol. 9:356-367.

Kim, Y., S. Oh, and S. H. Kim. 2009. Released exopolysaccharide (rEPS) produced from probiotic bacteria reduce biofilm formation of enterohemorrhagic Escherichia coli O157:H7. Biochem. Biophys. Res. Commun. 379:324-329.

Koo, H., M. L. Falsetta, and M. I. Klein. 2013. The exopolysaccharide matrix: A virulence determinant of cariogenic biofilm. J. Dent. Res. 92:1065-1073.

Ksontini, H., F. Kachouri, and M. Hamdi. 2013. Impact of Lactococcus lactis spp. lactis Biol. adhesion on pathogenic Bacillus cereus biofilm on silicone flowing system. Indian J. Microbiol. 53:269-275.

Kubota, H., S. Senda, N. Nomura, H. Tokuda, and H. Uchiyama. 2008 Biofilm formation by lactic acid bacteria and resistance to environmental stress. J. Biosci. Bioeng. 106:381-386.

Larsen, N., P. Nissen, and W. G. T. Willats. 2007. The effect of calcium ions on adhesion and competitive exclusion of Lactobacillus ssp. and E. coli O138. Int. J. Food Microbiol. 114:113-119.

Lee, H. S., S. E. Gilliland, and S. Carter. 2001. Amylolytic cultures of Lactobacillus acidophilus: Potential probiotics to improve dietary starch utilization. J. Food Sci. 66:338-344.

Liévin-Le Moal, V., R. Amsellem, A. L. Servin, and M.-H. Coconnier. 2002. Lactobacillus acidophilus (strain LB) from the resident adult human gastrointestinal microflora exerts activity against brush border damage promoted by a diarrhoeagenic Escherichia coli in human enterocyte-like cells. Gut 50:803-811.

López-Brea, M., T. Alarcón, D. Domingo, and J. Díaz-Regañón. 2008. Inhibitory effect of gram-negative and gram-positive microorganisms against Helicobacter pylori clinical isolates. J. Antimicrob. Chemother. 61:139-142.

Martin, N. H., S. C. Murphy, R. D. Ralyea, M. Wiedmann, and K. J. Boor. 2011. When cheese gets the blues: Pseudomonas fluorescens as the causative agent of cheese spoilage. J. Dairy Sci 94:3176-3183

McGroarty, J. A., L. Tomeczek, D. G. Pond, G. Reid, and A. W Bruce. 1992. Hydrogen peroxide production by Lactobacillus species: Correlation with susceptibility to the spermicidal compound nonoxynol-9. J. Infect. Dis. 165:1142-1144.

McLauchlin, J. 1987. Listeria monocytogenes, recent advances in the taxonomy and epidemiology of listeriosis in humans. J. Appl. Bacteriol. 63:1-11.

Monteagudo-Mera, A., I. Caro, L. B. Rodríguez-Aparicio, J. Rúa, M. A. Ferrero, and M. R. García-Armesto. 2011. Characterization of certain bacterial strains for potential use as starter or probiotic cultures in dairy products. J. Food Prot. 74:1379-1386.

Monteagudo-Mera, A., L. B. Rodríguez-Aparicio, J. Rúa, H. MartínezBlanco, N. Navasa, M. R. García-Armesto, and M. A. Ferrero. 2012. In vitro evaluation of physiological probiotic properties of different lactic acid bacteria strains of dairy and human origin. J. Funct. Foods 4:531-541

Morán, A., S. Gutiérrez, H. Martínez-Blanco, M. A. Ferrero, A. Monteagudo-Mera, and L. B. Rodríguez-Aparicio. 2014. Non-toxic plant metabolites regulate Staphylococcus viability and biofilm formation: A natural therapeutic strategy useful in the treatment and prevention of skin infections. Biofouling 30:1175-1182.

Mosqueda-Melgar, J., P. Elez-Martínez, R. M. Raybaudi-Massilia, and O. Martín-Belloso. 2008. Effects of pulsed electric fields on patho- 
genic microorganisms of major concern in fluid foods: A review. Crit. Rev. Food Sci. Nutr. 48:747-759.

Nagant, C., M. Tré-Hardy, M. Devleeschouwer, and J. P. Dehaye. 2010. Study of the initial phase of biofilm formation using a biofomic approach. J. Microbiol. Methods 82:243-248.

Navasa, N., L. Rodríguez-Aparicio, H. Martínez-Blanco, M. Arcos, and M. A. Ferrero. 2009. Temperature has reciprocal effects on colanic acid and polysialic acid biosynthesis in E. coli K92. Appl. Microbiol. Biotechnol. 82:721-729.

Nester, E. W. 2001. Microbiology: A Human Perspective. McGrawHill, New York, NY.

Olivares, M., M. P. Díaz-Ropero, R. Martín, J. M. Rodríguez, and J. Xaus. 2006. Antimicrobial potential of four Lactobacillus strains isolated from breast milk. J. Appl. Microbiol. 101:72-79.

Olvera-García, M., C. E. Serrano-Maldonado, and M. Quirasco. 2015. Detection of proteins with antibacterial activity produced by lactic acid bacteria. BioTecnología 19:25-43.

Otto, M. 2009. Staphylococcus epidermidis - The "accidental" pathogen. Nat. Rev. Microbiol. 7:555-567.

Otto, M. 2012. Molecular basis of Staphylococcus epidermidis infections. Semin. Immunopathol. 34:201-214.

Parassol, N., M. Freitas, K. Thoreux, G. Dalmasso, R. Bourdet-Sicard, and P. Rampal. 2005. Lactobacillus casei DN-114 001 inhibits the increase in paracellular permeability of enteropathogenic Escherichia coli-infected T84 cells. Res. Microbiol. 156:256-262.

Park, B., T. Iwase, and G. Y. Liu. 2011. Intranasal application of $S$. epidermidis prevents colonization by methicillin-resistant Staphylococcus aureus in mice. PLoS ONE 6:e25880.

Piard, J. C., and M. Desmazeaud. 1991. Inhibiting factors produced by lactic acid bacteria. Oxygen metabolites and catabolism endproducts. Lait 71:525-541.

Ramadan, H. H., J. A. Sanclement, and J. G. Thomas. 2005. Chronic rhinosinusitis and biofilms. Otolaryngol. Head Neck Surg. 132:414417.

Ranilla, M. J., M. D. Carro, S. López, C. J. Newbold, and R. J. Wallace. 2001. Influence of nitrogen source on the fermentation of fibre from barley straw and sugarbeet pulp by ruminal micro-organisms in vitro. Br. J. Nutr. 86:717-724.

Reid, G., and R. Friendship. 2002. Alternatives to antibiotic use: Probiotics for the gut. Anim. Biotechnol. 13:97-112.

Reid, G. 2006. Probiotics to prevent the need for, and augment the use of, antibiotics. Can. J. Infect. Dis. Med. Microbiol. 17:291-295.

Salminen, S., A. von Wright, and A. Ouwehand. 2004. Lactic acid bacteria. Pages 375-398 in Microbiological and Functional Aspects. 3rd ed. Marcel Dekker Inc., New York, NY.
Sanclement, J. A., P. Webster, J. G. Thomas, and H. H. Ramadan. 2005. Bacterial biofilms in surgical specimens of patients with chronic rhinosinusitis. Laryngoscope 115:578-582.

Saunders, S., A. Bocking, J. Challis, and G. Reid. 2007. Effect of Lactobacillus challenge on Gardnerella vaginalis biofilms. Colloids Surf. B Biointerfaces 55:138-142.

Scopel, M., W.-R. Abraham, A. L. Antunes, A. T. Henriques, and A. J. Macedo. 2014. Mevalonolactone: An inhibitor of Staphylococcus epidermidis adherence and biofilm formation. Med. Chem. 10:246-251.

Shornikova, A. V.. I. A. Casas, H. Mykkänen, E. Salo, and T. Vesikari. 1997. Bacteriotherapy with Lactobacillus reuteri in Rotavirus gastroenteritis. Pediatr. Infect. Dis. J. 16:1103-1107.

Silva, M., N. V. Jacobus, C. Deneke, and S. L. Gorbach. 1987. Antimicrobial substance from a human Lactobacillus strain. Antimicrob. Agents Chemother. 31:1231-1233.

Tahmourespour, A., R. Salehi, R. K. Kermanshahi, and G. Eslami. 2011. The anti-biofouling effect of Lactobacillus fermentum-derived biosurfactant against Streptococcus mutans. Biofouling 27:385-392.

Teneberg, S.. J. Angström, and A. Ljungh. 2004. Carbohydrate recognition by enterohemorrhagic Escherichia coli: Characterization of a novel glycosphingolipid from cat small intestine. Glycobiology 14:187-196.

Tuomola, E. M., A. C. Ouwehand, and S. J. Salminen. 1999. Human ileostomy glycoproteins as a model for small intestinal mucus to investigate adhesion of probiotics. Lett. Appl. Microbiol. 28:159-163.

Viswanathan, V. K., K. Hodges, and G. Hecht. 2009. Enteric infection meets intestinal function: how bacterial pathogens cause diarrhoea. Nat. Rev. Microbiol. 7:110-119.

Whitfield, F. B., N. Jensen, and K. J. Shaw. 2000. Role of Yersinia intermedia and Pseudomonas putida in the development of a fruity off-flavour in pasteurized milk. J. Dairy Res. 67:561-569.

Wijnands, L. M., J. B. Dufrenne, F. M. Rombouts, P. H. in 't Veld, and F. M. van Leusden. 2006. Prevalence of potentially pathogenic Bacillus cereus in food commodities in the Netherlands. J. Food Prot. 69:2587-2594

Yang, E., L. Fan, Y. Jiang, C. Doucette, and S. Fillmore. 2012. Antimicrobial activity of bacteriocin-producing lactic acid bacteria isolated from cheeses and yogurts. AMB Express 2:48-59.

Zhao, G., M. Nyman, and J. A. Jönsson. 2006. Rapid determination of short-chain fatty acids in colonic contents and faeces of humans and rats by acidified water-extraction and direct-injection gas chromatography. Biomed. Chromatogr. 20:674-682. 